\title{
A IDENTIDADE CULTURAL NAS CANTIGAS DE CAPOEIRA
}

\section{CULTURAL IDENTITY IN THE SONGS OF CAPOEIRA}

\author{
Marcela Guedes $\mathrm{Cabral}^{1}$
}

\begin{abstract}
Resumo: O presente artigo tem por base a pesquisa realizada para a obtenção do grau de mestre em Crítica Cultural, desenvolvida entre 2009 e 2011. Neste artigo tomamos por substrato de análise as cantigas de capoeira produzidas nos moldes tradicionais, por acreditar que estas expressam elementos da identidade cultural afro-brasileira, ao mesmo tempo em que participam da sua construção e afirmação. Considerando a feição interdisciplinar da Crítica Cultural, com isto, a abertura para uma gama de instrumentos metodológicos, dos quais pesquisa lançou mão de um conjunto técnico-instrumental que envolve, principalmente, o levantamento bibliográfico, e o estabelecimento de quadro de análise com base na metodologia das Representações Sociais.
\end{abstract}

Palavras-Chave: Identidade, Cultura, Afro-brasileiro, Capoeira, Cantigas.

\begin{abstract}
This paper is based on research conducted for the degree of Master in Cultural Critique, developed between 2009 and 2011. In this article we take for substrate analysis of the songs of capoeira produced in traditional ways, believing that they express elements of African-Brazilian cultural identity while participating in its construction and affirmation. Considering the interdisciplinary feature of Cultural Critique, with it, an openness to a range of methodological tools, including research resorted to a technical-instrumental ensemble that involves, mainly, the literature review and the establishment of the framework of analysis based on the methodology Social Representations.
\end{abstract}

Keywords: Identity, Culture, African-Brazilian, Capoeira, Songs.

\footnotetext{
${ }^{1}$ Mestra pelo Programa de Pós-Graduação em Crítica Cultural da Universidade do Estado da Bahia (UNEB). Professorado Assistente A do Curso de Bacharelado em Museologia na Universidade Federal do Pará (UFPA). E-mail: marcelagcabral@ hotmail.com
} 


\section{INTRODUÇÃO}

O presente artigo tem por base a pesquisa realizada para a obtenção do grau de mestre em Crítica Cultural, desenvolvida entre 2009 e 2011 pelo Programa de Pós-graduação em Crítica Cultural (Pós-Crítica), na Universidade do Estado da Bahia. Neste artigo, as cantigas de capoeira serão abordadas como documentos que nos oferecem compreensão acerca das representações e das identidades culturais afro-brasileiras, sobretudo entre os capoeiristas que se formaram, atuam ou atuaram em Salvador. A partir destes documentos, de composição dos próprios mestres e capoeiristas, principais sujeitos desta manifestação e considerando suas vivências, pontos de vista e valores veiculados nestas cantigas, estabelecemos as bases para análise e compreensão de como se apresentam e atuam os elementos de origem afro-brasileira nas cantigas de capoeira. Para tanto se buscou pensar contexto de produção, execução e aprendizagem das cantigas de capoeira em Salvador.

Tomamos por substrato de estudo as cantigas de capoeira produzidas nos moldes tradicionais $^{2}$, por acreditar que estas expressam elementos da identidade cultural afro-brasileira, ao mesmo tempo em que participam da sua construção e afirmação. Notamos a relação entre a identidade afro-brasileira e as músicas de capoeira, através do conteúdo e do discurso das letras das cantigas, que expressam diversos elementos desta identidade, a partir dos quais definimos as categorias representacionais aplicadas na análise das cantigas. Observamos também que, através de valores e vivências, configura-se e reconfigura-se essa identidade cultural, e que muitas destas cantigas são produzidas com base nestes, uma vez que a música tradicional da capoeira expressa estes valores e vivências dos afro-brasileiros e também aquilo que se construiu como fundamentos da capoeira, que por sua vez refletem esses conjuntos de elementos. Deste modo, para a análise das cantigas, foi lançado mão ao estudo do que se conhece como valores civilizatórios afro-brasileiros e dos estudos sobre a formação da identidade cultural afro-brasileira.

\footnotetext{
${ }^{2}$ Como moldes tradicionais são compreendidas as modalidades das cantigas (ladainha, quadras, corridos, chulas e louvação), com temáticas que versam ou giram em torno dos elementos culturais afro-brasileiros.
} 
Considerando a feição interdisciplinar da Crítica Cultural, e, com isto, a abertura para uma gama de instrumentos metodológicos, a fim de compor a metodologia deste trabalho, a pesquisa lançou mão de um conjunto técnico-instrumental que envolve, principalmente, o levantamento bibliográfico, observação etnográfica e o estabelecimento de quadro de análise com base na metodologia das Representações Sociais.

Pontuamos aqui que a identidade cultural afro-brasileira é construção social, elaborada a partir das referências dos diversos grupos étnicos africanos que tiveram seus representantes trazidos, como escravos, para o Brasil. Considerando a conjuntura da escravidão colonial e a fragmentação das referências institucionais dos africanos, aqui escravizados ${ }^{3}$, como fato que não lhes permitiu a continuidade das suas culturas, percebemos este contexto como elemento fundamental que possibilitou a criação e desenvolvimento não somente da capoeira, como também do universo da cultura afro-brasileira.

\section{CAPOEIRA E IDENTIDADE CULTURAL AFRO-BRASILEIRA}

Neste sentido, podemos afirmar que a capoeira, como a conhecemos, só pôde ser desenvolvida no contexto da escravidão. Este fato lhe imprimiu uma série de significados e características que a distancia do $n^{\prime}$ golo ${ }^{4}$, que não se resume aos golpes e contragolpes, mas também que envolve uma História e uma concepção de mundo, construídas sobre um tenso e imbricado contexto de relações sociais. Além disso, cumpre ressaltar que não somente a capoeira, mas também outras manifestações da cultura afro-brasileira tiveram em seu processo de construção influências desse contexto. Por maior que tenham sido as influências dos elementos trazidos nas memórias dos escravizados, as construções que ocorreram no Brasil através do tangenciamento, diálogo entre manifestações e tradições entre indivíduos de grupos africanos de origens diferentes, amalgamaram-se em fenômenos sociais que não se

\footnotetext{
${ }^{3}$ Segundo Sérgio Buarque de Holanda (1999), os principais grupos culturais de africanos trazidos para o Brasil foram os dos grupos linguísticos Bantu e Sudaneses, dos quais se originavam diversos dialetos e ocupavam vasta área do território africano.

${ }^{4} \mathrm{O}$ N'golo é um jogo ritualístico praticado por alguns grupos que vivem no Sul de Angola. Seus movimentos assemelham-se aos da capoeira e, por isso, o historiador Luiz da Câmara Cascudo atribui ao N'golo a origem da capoeira. (REGO, 1968, p. 19; ABREU e CASTRO, 2009, p.21, OLIVEIRA, 1971, p. 69).
} 
apresentavam em sua completude, impossibilitando a perspectiva de um continnum transatlântico.

Desta forma, usando o que poderíamos chamar de "princípio filosófico da ginga da capoeira", o jogo de avanço e recuo e de olhares enviezados em forma de negociações, estabeleceram-se não somente elementos e símbolos que formam a roda da capoeira, do maculelê, do samba, da batucada, como também a outros aspectos da cultura dos sujeitos envolvidos, a exemplo, a cosmovisão e os modos de vida afro-brasileiros. A cultura e a identidade afro-brasileira foram construídas a partir da busca de se reorganizar os modos de vida africanos, no contexto da escravidão. Vemos que, no Brasil, as manifestações africanas que cruzaram o Atlântico, na memória dos negros escravizados, passaram por diversas modificações, ressignificações e adaptações e se institucionalizaram de formas diferentes das existentes na África. Grupos distintos, algumas vezes rivais, uniram-se e impuseram resistência à invasão das mentes, ao processo de aculturação e à obliteração decorrentes da escravidão e do racismo $^{5}$ e, a partir desta conjuntura, articularam seus valores com o que havia de vivo em suas memórias. Observo, aqui, que a luta pela igualdade e respeito aos afrodescendentes ainda não está concluída e ainda hoje se fazem necessárias lutas diárias em outras frentes, como no âmbito social, cultural e jurídico.

Os valores culturais vindos da África permeiam e se manifestam na memória coletiva, na cultura, na lógica dos pensamentos e comportamentos, enfim, nos modos de vida dos afrodescendentes, expressando-se de formas diferentes entre os diversos grupos afro-brasileiros. Neste sentido, Mintz e Price salientam a heterogeneidade do continente africano, bem como consideram limitada a possibilidade de atuação destes valores, observam que:

Uma herança cultural africana, largamente compartilhada pelas pessoas importadas por uma nova colônia, terá que ser definida em termos menos concretos, concentrando-se mais nos valores e menos nas formas socioculturais, e até tentando identificar princípios 'gramaticais' inconscientes que pudes-

\footnotetext{
5 Consideramos aqui "raça" como um conceito histórico sociológico utilizado muito mais para tratar características fenotípicas que genotípicas, do qual o conceito de "raça" caiu, permanecendo, tão somente e infelizmente, o preconceito. Segundo Munanga, “[...] se cientificamente 'raça' é um conceito pouco significativo, política e ideologicamente ele é muito significativo, pois funciona como uma categoria etnosemântica, isto é, política e econômico-social de acordo com a estrutura de poder em cada sociedade multirracial” (MUNANGA, 1990:110).
} 
sem estar subjacentes à resposta comportamental e fossem capazes de moldá-la. (MINTZ e PRICE, 1992:27 - 28).

Assim, compreendemos não somente a capoeira, mas toda a gama de manifestações e instituições afro-brasileiras, como uma criação dos africanos das várias nações que estavam no Brasil na condição de escravizados ou ex-escravizados, que foi desenvolvida por seus descendentes como uma forma de resistir à opressão que lhes era imposta, e que teve seu desenvolvimento continuado de modo a ser transformada e disseminada com o decorrer do tempo, compartilhando uma cultura, ao mesmo tempo em que era construída essa nova cultura, ressignificando fragmentos de várias heranças, agregando ou mantendo elementos, como observamos no caso da capoeira, seu caráter lúdico, ritual e de luta.

A capoeira, mistura de dança, luta e jogo, acompanhada por música far-se-ia passar facilmente por dança, não fosse sua carga histórica de luta e resistência, não fosse a necessidade de momentos lúdicos para aliviar as tensões cotidianas com jogos e brincadeiras. Por isso ela é luta, dança e jogo ao mesmo tempo e sendo um, não deixa de ser outro.

A música na capoeira atua como expressão e elemento de sedimentação da cultura afrobrasileira. O soar do berimbau entoando uma ladainha, quadra ou corrido, muitas vezes evoca da memória coletiva a opressão pela qual passaram os negros escravizados, ao mesmo tempo exprime a recusa em esquecer, e a ânsia de superação das sequelas sociais produzidas no período da escravidão. Estabelecendo deste modo outras formas de luta e resistência, a partir da capoeira, por meio dos seus fundamentos, músicas e cantigas, as quais, atualmente, se unem às formas de organização social como o movimento negro e a ações antirracistas.

Biancardi (2006:08-109) afirma que a música vocal da capoeira ganhou importância a partir da década de 30 do século passado, e sua produção não era tão específica como se pode pensar. Lembramos aqui que foi nos anos 30 do século XX que a capoeira, nos moldes baianos, foi "elevada" à categoria de esporte nacional pelo então presidente Getúlio Vargas (REIS 2000, SOARES, 1962). No jogo de capoeira eram também cantadas cantigas de roda, do samba de roda corrido que, aos poucos, foram passando a ganhar destaque, e chegando a fazer parte do ritual do jogo. Nesta perspectiva, notamos que as cantigas tradicionais da capoeira são uma invenção, relativamente recente. Considerando o período no qual as cantigas ganharam maior destaque, podemos também intuir mais uma negociação: a capoeira nos moldes 
baianos, ainda mais embelezada com os versos cantados, chamavam a atenção para a feição de jogo e dança, enquanto o caráter agressivo e violento de luta, no que seria o modelo carioca, era rechaçado e combatido como status de esporte nacional.

De modo geral, cantigas tradicionais da capoeira são repletas de elementos que remetem à identidade cultural afro-brasileira e às representações sociais pertinentes a um segmento social particular, os capoeiristas ou capoeiras. Tomadas como produto da criação destes sujeitos, cuja grande parte é formada por afrodescendentes, podemos observar através destas cantigas, como os capoeiristas veem a si próprios enquanto sujeitos políticos atuantes dentro da sociedade.

\section{A METODOLOGIA}

As categorias de análise foram estabelecidas de acordo com a metodologia oferecida pelas Representações Sociais, observando a recorrência de elementos como expressões e ideias significativas para o grupo de capoeiristas estudado. $\mathrm{O}$ estabelecimento das categorias procurou por estes dois indicadores nas cantigas de capoeira reproduzidas nos treinos através de CD ou na iniciação às músicas e cantos da capoeira e executadas nas rodas observadas. Percebemos assim, estas cantigas como produção e expressão simbólica, nas quais os capoeiristas de Salvador falam de si, dos elementos que compõem seu mundo e o modo como se representam; como parte do fenômeno cultural da capoeira, como forma simbólica estruturada em contexto específico, tanto no momento da produção quanto da recepção das cantigas de capoeira, nos quais se expressam suas representações sociais como capoeiristas afro-brasileiros. Uma vez estabelecidas as categorias, para melhor nortear as análises, lançamos mão de entrevistas com alguns mestres de capoeira, frequência a rodas de capoeira, tanto nos centros turísticos quanto em bairros periféricos de Salvador, e os conceitos do que se apresentam como valores civilizatórios afro-brasileiros, os quais apresentaremos a seguir.

As cantigas de capoeira em seu discurso podem ser percebidas como elementos que expressam aspectos significativos da cultura e da identidade afro-brasileira daqueles que se encontram inseridos no contexto de produção e recepção destas. Deste modo, uma investigação acerca das representações sociais vinculadas e veiculadas nessas cantigas nos permite identificar aspectos da identidade afro-brasileira que envolvem os capoeiristas como grupo. 


\title{
3 OS VALORES CIVILIZATÓRIOS AFRO-BRASILEIROS
}

Antes de prosseguirmos rumo à análise das cantigas, no sentido de acurar a percepção do leitor na identificação a alguns aspectos relacionados a herança cultural africana, apresentamos alguns dos chamados valores civilizatórios afro-brasileiros, que se relacionam diretamente à construção das identidades afro-brasileiras, os quais permeiam as cantigas da capoeira.

A noção de valores africanos foi elemento fundamental na construção do amplo patrimônio cultural e das identidades afro-brasileiras e atuaram tanto no consciente quanto no inconsciente. Estes valores agiram na formação da identidade, da autocompreensão, da sociedade brasileira. Como conjunto de elementos de significações diversas (ética, religiosa, social, corporal, científica, dentre outras) estes valores nortearam a reorganização da vida dos grupos de indivíduos escravizados. Deste modo, percebemos tais valores como elementos que atuaram na criação das novas formas culturais desses indivíduos desterrados, e de seus descendentes, na medida em que buscavam reorganizar suas vidas no Brasil. Tais criações e recriações foram configurando-se através dos muitos processos de interação que resultaram em novas formas culturais e novas instituições.

A princípio, tais valores, diferenciais na composição da identidade afro-brasileira, se distinguem ou mesmo se opõem a muitas das concepções e valores ocidentais, como por exemplo, ao individualismo, à busca obcecada pela vantagem e pelo lucro capitalista e ao consumismo desenfreado, imposto pela cultura de massas, que ao mesmo tempo foram e são institucionalizados. Nesse sentido, cabe a fala de Gilberto Gil (2007), no que toca às relações de solidariedade como princípio africano:

\begin{abstract}
A predominância nesses mundos negros de uma grande diversidade de projetos não produziu uma Torre de Babel exatamente porque não predominou a lógica materialista de Marx, pela qual os interesses objetivos soldariam as solidariedades de grupo ou classe. O cimento era outro. Acredito que nossas solidariedades sempre foram uma expressão de nossas identidades que vicejaram em uma cultura afro-global, o que significa dizer que as representações que construímos de nós mesmos foram mais fortes do que as condições de exploração e de pobreza a que fomos submetidos. (GIL, 2007:11).
\end{abstract}

Deste modo, percebemos que a cultura afro-brasileira é resultado da interação dos povos da África que se encontravam no Brasil sob a condição de escravizados. Assim, o contexto da 
escravidão no Brasil, com suas formas de dominação, aculturação e de certo modo negociação, atuou como elemento fundamental na construção da cultura afro-brasileira, pois em outra situação o resultado jamais seria o mesmo. Por esse motivo, é dado destaque, neste trabalho, a alguns elementos do conjunto de valores e princípios que atuaram na estruturação deste processo identitário, os quais podemos observar expressos nas cantigas de capoeira. Lembramos, porém, que estes valores não atuam ou se manifestam isoladamente, mas em conjunto, de forma integrada, como se faz perceber em muitos outros aspectos da vida e da visão de mundo dos afrodescendentes, como herança dos que vieram do continente africano.

Dentre o vasto rol do que podemos considerar como valores civilizatórios afrobrasileiros, destacamos alguns, que nos auxiliaram na análise das cantigas:

A religiosidade, que pode ser compreendida como um sentimento ou uma tendência natural do homem a relacionar-se com o divino ou sobrenatural;

A oralidade, que sempre esteve e continua presente em muitas culturas, ainda é a grande responsável pela transmissão e preservação de vários conhecimentos, tradições e modos de vida;

A memória, por ser fruto de uma experiência com o tempo, relaciona-se diretamente com a noção de temporalidade e possui três funções básicas: adquirir informações, armazenar estas informações e evocar, rememorar ou lembrar estas informações. O que justifica todo o processo que compõe esta faculdade é a sua capacidade de localizar o ser humano em um tempo-espaço, dando sentido à sua biografia e existência. Na cultura africana e afro-brasileira, tanto a oralidade quanto a memória ganham sentido de valor civilizatório, conquanto atuam nestes grupos como elementos pertencentes a uma outra dimensão da realidade, na qual se localizam na realidade subjetiva e intersubjetiva, as quais envolvem o universo místico, ancestral e de forças que justificam estas faculdades como valores em seus processos existenciais, históricos, intelectuais sociais e culturais e com a realidade objetiva;

A ancestralidade liga-se ao autoconhecimento, à ideia de origem, deste modo, à identidade, ao passado e ao nosso futuro;

A ancianidade, de acordo com Marco Aurélio Luz (2000), sedimenta-se neste valor grande parte do conhecimento sobre o axé e a origem do seu grupo. Ao mais velho cabe a 
missão de transmitir aos mais novos sua sabedoria e sua experiência de vida, também aos primeiros é confiada a missão de manter viva a memória dos ancestrais;

O axé ou "princípio da força vital" pode ser compreendido se relacionado diretamente com oralidade, à ancestralidade e à circularidade a partir do que observa Luz (2000), com base no pensamento do artista plástico e escritor baiano, Deoscoredes M. dos Santos, mais conhecido como Mestre Didi:

Axé é um conceito que exprime a idéia de forças circulantes capazes de engendrar a criação e a expansão da vida. Ele implica na idéia de restituição que se concretiza através do conceito de ebó, isto é, oferenda ou sacrifício (LUZ, 2000:32);

A circularidade permite a transformação das forças e o retorno destas. Na capoeira vemos a circularidade na "volta no mundo", quando o capoeirista caminha em círculo dentro da roda cumprimentando seus participantes, no aú6, dentre outros golpes que aludem à ideia de movimento de fluxo e refluxo, de vai e volta e do retorno das forças e energias;

A musicalidade é considerada por Trindade (2005) como um valor afro-brasileiro que está em permanente interação, justificando que a presença da música e da movimentação do corpo são fundamentais em muitas manifestações dessa cultura, e se estabelecem como condições sem as quais não pode existir, em seu sentido pleno, as comemorações da vida social, os cultos religiosos do candomblé ou a roda de capoeira.

Os valores culturais afro-brasileiros fazem parte não somente do mundo da capoeira, mas de inúmeras outras manifestações culturais afro-brasileiras. Percebemos que estes valores não se encontram ou atuam isoladamente uns dos outros, mas perpassam-se e interagem uns com os outros. Estes valores fazem-se presentes em diversas culturas, contudo seus símbolos, significações e relações são estabelecidos de modos diferentes em decorrência das marcas históricas, sociais e da formação da própria cultura que envolve uma série de construções de

\footnotetext{
${ }^{6} \mathrm{O}$ aú é um dos movimentos básicos e mais conhecidos da capoeira e pode ser realizado na entrada no jogo propriamente dito, com na "saída de aú" ou combinado com outros golpes. O aú consiste realizar um meio giro lateral com todo o corpo, apoiando o corpo com as mãos no chão e girar com as pernas para cima sobre o corpo, caindo com os pés no chão. Na modalidade angola, as pernas no ato do giro encontram-se flexionadas, enquanto na regional as pernas ficam retas.
} 
ordem simbólica, afetiva e mitológica que representam os indivíduos e fazem com que estes se reconheçam.

No universo da cultura afro-brasileira, os contextos da diáspora, da escravidão, e das desigualdades e do racismo, estes últimos ainda presentes, somam-se aos valores civilizatórios de origem africana que atuam como referência na formação das identidades construídas pelos africanos e afrodescendentes. Melhor compreendendo estes valores e a atuação destes na construção da identidade afro-brasileira, voltemos a tratar das cantigas, observando como estes valores são expressos pelos capoeiristas.

\section{AS ENTREVISTAS}

Com a finalidade de melhor compreender os aspectos relacionados ao universo da capoeira e o significado de suas cantigas, foram realizadas entrevistas com seis mestres/professores de capoeira de Salvador. Por um lado, estes mestres apresentam perfis distintos, no que diz respeito aos objetivos do grupo do qual fazem parte, quanto à localização dos espaços onde ocorrem os treinos ou aulas, o público (alunos) que atingem, faixa etária, etc. Por outro lado, convergem em relação ao sentido que, em geral, atribuem à capoeira, à expressão da identidade cultural afro-brasileira, às representações sociais que constroem sobre si, como sujeitos desta cultura, e ao uso que fazem das cantigas de capoeira como forma de expressão de ideias e sentimentos.

Os seis mestres entrevistados atuam na cidade de Salvador, no Centro Histórico de Salvador (Pelourinho), na Avenida Carlos Gomes (Centro), nos bairros da Federação, da Cidade Nova, de Cosme de Farias e da Massaranduba. Todos os entrevistados são do sexo masculino, com idades, na época das entrevistas, entre 35 e 77 anos, com média de 30 anos na prática da capoeira, com iniciação na infância. Exceto mestre Marcelo de João Pequeno que foi iniciado aos 30 anos.

O Mestre Dnei Gingarte (Elinei Jorge Santa Rosa) é discípulo do Mestre "Um por Um". Iniciou-se na capoeira aos sete anos, jogando capoeira de rua. Atualmente, com 28 anos de capoeira, atua há sete como mestre no bairro da Cidade Nova. Na entrevista com o Mestre Dinei, foi possível observar que a maior parte dos alunos é formada por crianças na faixa de 
seis a quatorze anos, com a presença de poucos adultos com idades entre 30 e 40 anos. Em seus treinos, na AGICUCAR, faz uso do CD player para ambientar a segunda parte da aula, uma vez que a primeira parte consiste em passar a sequência de golpes a qual cada aluno pratica individualmente.

O Mestre Valdec (Valdec Sidnei Santos Cirne) tem hoje 40 anos de idade e 29 de capoeira. Aos 18 já dava aulas de capoeira como treinel7. Lembra-se de ter sido considerado como "o mais novo dos velhos mestres e o mais velho dos novos". Iniciou na capoeira junto ao Grupo Filhos de Angola, em 1982, como aluno do Mestre Roberval e do Mestre Laércio, aos nove anos de idade. Em 27 de Outubro de 1997 fundou o Grupo Bantu de Capoeira Angola, atualmente com dois núcleos em Salvador, localizados no Pelourinho e em Cosme de Farias; dois núcleos na Alemanha, em Berlim e Mainz; outro núcleo na Colômbia, em Bogotá, e um nos Estados Unidos, no Estado do Michigan. O Mestre Valdec marcou seu posicionamento como um mestre tradicionalista, em suas próprias palavras:

\begin{abstract}
Nós temos alguns segmentos de capoeira angola aqui na Bahia. Isso é bem segmentado. Então é assim, tem o segmento do qual eu faço parte de capoeira angola, que é um pouco mais tradicionalista, então a gente procura não só manter vivas não só as canções antigas, como também compor em cima da tradição. [...] E tem segmentos da capoeira angola que são mais ligados às questões raciais, que eu até sou um pouco ligado, mas que falam mais de religiosidade, falam mais de questões atuais também, política etc. E tem um segmento que posso falar de todo mundo, regional, contemporâneo, o que for que você possa chamar, que eles fazem música aleatoriamente assim, que tenha ritmo, que tenha alguma coisa a ver, eles pegam um assunto que tenha a ver com o interesse, que pode ser uma música de axé e pode ser uma música de capoeira. (Mestre Valdec, em entrevista concedida para a pesquisa)
\end{abstract}

Mestre Marcelo de João Pequeno (Marcelo Maciel Cabral) iniciou-se na capoeira aos trinta anos e teve convivência intensa com o mestre João Pequeno de Pastinha, seu mestre. Hoje tem 59 anos de idade e 29 anos de capoeira. Seu grupo não tem nome, é formado em sua maioria por alunos da Universidade Federal da Bahia (UFBA) graduandos, mestrandos e egressos. O espaço onde ocorrem os treinos é cedido pela UFBA, no pátio das faculdades de

\footnotetext{
${ }^{7}$ Treinel é a primeira graduação da capoeira angola. Designa aluno mais experiente, que domina em nível básico os fundamentos da capoeira, os movimentos, os instrumentos e o canto da capoeira angola, de modo que este aluno já pode dar aulas e assumir turma como treinel, mas ainda ligado ao nome do mestre e sua academia.
} 
Arquitetura, Farmácia e Biologia, e as aulas ocorrem de segunda a sexta-feira, normalmente, seguindo o calendário letivo da UFBA.

Em suas aulas não faz uso de aparelho de reprodução de áudio. Normalmente, o treino segue sem música. Apenas, o treino dos movimentos e suas correções. Ao término desta parte, o mestre arma8 o berimbau, e executa alguns toques da capoeira angola enquanto os alunos em dupla - treinam os movimentos. Suas cantigas são de feição subjetiva e partem de experiências de vida, dramas pessoais e da observação do contexto da roda. Nas palavras do mestre:

A pessoa tem que fazer suas próprias ladainhas, porque ladainha é uma coisa muito particular. É uma coisa muito da pessoa, subjetiva - como dizem, não é? É muito de cada um mesmo. Você pode até cantar a música de alguém e tal, até para prestar uma homenagem e tudo, mas eu não gosto não, eu mesmo gosto de ter minhas ladainhas. Eu vou cantando as minhas ladainhas. (Mestre Marcelo de João Pequeno em entrevista concedida à pesquisa)

As cantigas são passadas nas conversas entre mestre e aluno, antes ou após as aulas, nas rodas que fazem ou visitam junto como o grupo. Este mestre marca também que é preciso de uma boa bateria e uma boa música para "se fazer um jogo realmente bonito", pois os jogadores que estão na roda buscam sincronia com a música que está sendo tocada.

Mestre Valmir Damasceno, iniciou na capoeira com o Grupo de Capoeira Angola Pelourinho, como discípulo do Mestre Moraes. Atualmente, aos 47 anos de idade e 31 de capoeira, é mestre da Fundação Internacional Capoeira Angola - FICA, que tem núcleos em diversos países. Em Salvador, o local dos treinos está localizado na Avenida Carlos Gomes, no Centro da cidade, onde realizamos a visita e a entrevista. O corpo de alunos deste mestre é formado por adultos. Considerando que os horários das aulas que se concentram à noite, entre as 19 h00 e 22 h00 horas, e a localização da Fundação, não favorecem a presença de crianças. As cantigas que são cantadas em Salvador por esse grupo são também cantadas nos outros núcleos no exterior, para isso a Federação edita cadernos com suas cantigas, sempre em português.

\footnotetext{
${ }^{8} \mathrm{O}$ mestre Marcelo costuma levar o berimbau desmontado em suas partes, cabaça, biriba e arame e o arma antes de tocá-lo, desmontando-o novamente antes de sair do local.
} 
O mestre Valmir, embora tenha diversos instrumentos de capoeira na sede da Fundação, prefere na hora do treino, dos movimentos, fazer uso do aparelho de reprodução de áudio, um mp3, no qual tem gravado tanto cantigas tradicionais dos grandes mestres da capoeira angola, quanto as cantigas criadas pelo grupo da Federação. As aulas com os instrumentos são realizadas segundo mestre Valmir, entre duas e três vezes por semana, ocupando uma parte da aula apenas. Faz questão que a disposição dos instrumentos esteja na mesma disposição das rodas organizadas pela FICA.

Mestre Pelé da Bomba, conforme suas próprias palavras, "Apresentando a mim mesmo: Eu me chamo Natalício Neves da Silva, eu nasci em 1934, conhecido hoje em dia dentro da roda da capoeira como Mestre Pelé da Bomba.” (Mestre Pelé da Bomba em entrevista concedida à pesquisa). Iniciou na capoeira por volta dos nove anos de idade como aluno do mestre Bugalho, nas aulas que aconteciam "na rampa do Mercado Modelo. O Mercado Modelo ve1ho, não o novo. Antes de incendiar" (Trecho da entrevista do Mestre Pelé da Bomba concedida durante a pesquisa). Seu nome de capoeira vem da profissão que exerceu até ser aposentado, bombeiro. Como bombeiro e capoeirista, chegou a ensinar a capoeira a seus colegas de quartel e lembra-se do dia em que ajudou a combater a um dos incêndios que ocorreu no Mercado Modelo, local onde aprendeu a jogar capoeira. Hoje aos 79 anos, tendo completado 70 anos de capoeira é considerado um dos mestres mais antigos da Bahia. Possui uma academia no Forte da Capoeira, no bairro do Santo Antônio Além do Carmo e uma que funciona no Pelourinho, no primeiro andar da sua loja de produtos e lembranças da Bahia. O quadro de alunos do Mestre Pelé é bem diversificado, principalmente na academia que funciona no Pelourinho. Ele tem turmas formadas por crianças que moram no entorno, turmas formadas por adultos que vivem em Salvador, e turmas formadas por turistas.

Mestre Pelé da Bomba não faz uso de CD ou outro tipo de aparelho de reprodução de áudio em suas aulas. A aula de movimentos é orientada enfatizando os golpes e contragolpes, as defesas e o gingado, bem como o nome de cada um dos movimentos. Nas aulas de instrumento, que ocorrem separadamente às aulas de movimento, o mestre ensina os toques e as cantigas através da demonstração e repetição do aluno. As cantigas são passadas de modo semelhante, quando o mestre canta e a turma entoa o coro, e com o passar do tempo os alunos mais experientes podem cantar as cantigas e tocar o gunga. 
Bambam Capoeira é como é conhecido Idelvan Barbosa da Silva no mundo da capoeira. Nascido no Piauí tem 40 anos de idade e 32 de capoeira. O Mestre Bambam Capoeira é responsável pelo núcleo da Escola de Capoeira Filhos de Bimba no bairro de Massaranduba onde desenvolve um trabalho com crianças carentes do bairro através do Projeto Capoerê. Seu primeiro contato com a capoeira foi aos oito anos em Teresina - Piauí. Aos 18 anos entrou para o Exército, onde continua atuando como oficial. Por este motivo mudou de cidade algumas vezes e em cada lugar que era designado a ir buscava se integrar em um grupo de capoeira, assim praticou com vários mestres de diferentes modalidades de capoeira (abadá, senzala9, regional). Em 1998, foi formado pelo Grupo de Capoeira Filhos de Bantu em Corumbá - Mato Grosso do Sul, com o Mestre China. Mestre Bambam Capoeira pondera ao dizer que "a todos tenho como referência, mas em especial ao mestre Garrincha que hoje me fez entender mais um pouco o que significa ser capoeira regional.” Após dez anos de capoeira regional, o Mestre Bambam Capoeira formou-se novamente em 2013 como discípulo do Mestre Garrincha, pela "Filhos de Bimba". O Mestre Bambam Capoeira considera as cantigas de grande importância para a transmissão da História e dos fundamentos da capoeira. Faz uso do CD em suas aulas e diz que - na capoeira regional - os discípulos são orientados a sempre seguir os fundamentos da capoeira, inclusive na parte musical.

\section{A ANÁLISE DAS CANTIGAS}

Foi selecionada uma vasta lista de cantigas de capoeira, com base em discos (CD's e LP's), documentários, no arquivo de Emília Biancardi do Festival de Música Tradicional da Capoeira (primeira e segunda edição) e no livro do capoeirista Shinji Kubohara, "Vamos cantar, camará", o qual apresenta a transcrição de diversas cantigas a partir de CD's e LP's de cantigas de capoeira. Transcritas a partir do áudio ou copiadas de livros ou sites que apresentam o áudio e a letra, as cantigas foram tabeladas considerando os temas recorrentes estabelecidos como categorias. Atentamos aqui para o fato de que, muitas vezes, mais de uma categoria é abordada na mesma cantiga, nestes casos as cantigas foram inseridas em mais de uma categoria e sinalizado o trecho que as vinculava ao tema.

\footnotetext{
9 São novas modalidades de capoeira que surgiram posteriormente às modalidades "regional" e "angola". Trazem algumas diferenças práticas e teóricas, mas em si, também são compreendidas como capoeira.
} 
Outro ponto a observar, diz respeito às cantigas que possuem mais de uma versão, permanecendo o mesmo nome, a exemplo de "Paranauê". Nestes casos todas as versões encontradas foram transcritas, tabeladas e sinalizadas como versão 1 (V.1), versão 2 (V.2) e assim por diante, sinalizado o trecho que a diferencia e, como as demais, inseridas em tabela segundo os mesmo critérios.

O estabelecimento das categorias teve por objetivo sistematizar a análise das cantigas de capoeira, no tocante aos aspectos referentes à compreensão da sua produção, transmissão e recepção. Desta forma, consideramos que pretende-se conhecer o que o capoeirista, autor das cantigas, procura expressar - intencionalmente, ou não, - em termos de conteúdo e ideologia, principalmente no que diz respeito à identidade cultural afro-brasileira. Tomando as cantigas executadas em Salvador, cidade considerada entre os capoeiristas como "a Meca da capoeira" - já que assim foi construída dentro da ideia de esporte nacional desde os anos trinta corroborado pelo fato de possuir número expressivo de afrodescendentes - buscamos conhecer quais são os valores culturais afro-brasileiros, transmitidos nas cantigas de capoeira; o que da História do negro no Brasil é passado nestas cantigas; quais as representações sociais que estas produzem e reproduzem, com base nessas questões estabelecemos o quadro de categorias de análise criado para esta pesquisa.

As categorias e subcategorias são as seguintes: Primeira categoria: Valorização da Identidade Cultural Afro-brasileira, com as subcategorias: Valores afro-brasileiros e Tradição; Segunda categoria: Pessoas de referências, subcategorizada em Mestres e Heróis; A terceira categoria trata dos Elementos do Mundo da Capoeira, com as seguintes subcategorias: Ginga, Instrumentos e Fundamentos; A quarta categoria pontua O Espaço, a Bahia, o Brasil ; a África e Angola são as subcategorias; A quinta categoria pontua as Narrativas, dividida em duas subcategorias: História do Negro e as Experiências e Causos; Por fim, a sexta categoria: ela envolve as Definições Sobre a Capoeira que se apresenta como Esporte, Arte, Luta, Cultura e Ritualidade, definidas como subcategorias.

Pontuamos no quadro de categorias a expressão da Valorização da Identidade Cultural Afro-brasileira que permeia - se não todas - imensa parte das cantigas. Muitas vezes percebemos que esta valorização se dá através da oposição preconceito "racial" - História. Por esta 
razão, dentre as demais categorias, daremos maior enfoque a esta, com destaque para a emblemática cantiga do Mestre Ezequiel, discípulo do Mestre Bimba, que diz:

\author{
Às vezes me chamam de negro, \\ Pensando que vão me humilhar. \\ Mas o que eles não sabem \\ É que só me fazem lembrar \\ Que eu venho daquela raça \\ Que lutou pra se libertar, \\ Que eu venho daquela raça, \\ Que lutou pra se libertar - \\ Que criou o maculelê, \\ Que acredita no candomblé, \\ Que tem o sorriso no rosto, \\ A ginga no corpo e o samba no pé ! \\ Que tem o sorriso no rosto, \\ A ginga no corpo e \\ o samba no pé ! \\ Que fez surgir de uma dança, \\ Uma luta que pode matar : \\ Capoeira, arma poderosa, \\ Luta de libertação, \\ Brancos e negros na roda \\ se abraçam como irmãos.
}

(Mestre Ezequiel in KUBOHARA, 2000)

Deste modo, podemos perceber na cantiga apresentada que o preconceito não é ignorado pelo compositor, pois parte de experiências concretas do autor com a discriminação. Neste aspecto, a cantiga também faz uma denúncia. O preconceito é mostrado como primeiro elemento, e isso não pode ser negligenciado, pois é a partir da colocação "às vezes me chamam de negro/ pensando que vão me humilhar" que se desenvolve a cantiga. O "às vezes", sinalizando mais de uma vez, também pode ser considerado como sinônimo de "muitas vezes". "Às vezes" entende-se como algo corriqueiro, que acontece sem dar importância à sua periodicidade. Nesse caso é expresso o preconceito, a discriminação e a tentativa de agressão verbal com o uso do vocativo "negro" como algo que se apresenta no cotidiano. A intenção de chamar "de negro," com a finalidade de humilhar, reflete, contudo, - para o negro consciente de sua afro-descendência - nada mais que a ignorância de quem o faz: algo a ser combatido. O termo "pensando", mostra que existe a intenção de quem profere, mas não tem seu objetivo alcançado, uma vez que quem é chamado de "negro" não se sente humilhado, mas envaidecido, por conhecer e valorizar sua descendência. No caso da cantiga, o autor marca a intenção 
de humilhar, associado ao "chamar de negro". Assim percebemos ideias e imagens pejorativas, oriundas da convivência com constructos sociais racistas, e a manifestação da ignorância por parte de quem usa o termo "negro" com a intenção de humilhar.

"Mas o que eles não sabem/É que só me fazem lembrar / Que eu venho daquela raça/ Que lutou pra se libertar.” Embora aqui se apresente a ideia de raça, não se trata de uma referência ao seu conceito biológico, mas ao sentido de "raça" como uma construção social, conforme adverte Munanga : "Os conceitos de negro e de branco têm um fundamento etnosemântico, político e ideológico, mas não um conteúdo biológico.” (MUNANGA, 2004:52).

Outro aspecto que podemos destacar nesta cantiga, recorrente em outras tantas, relaciona-se à contestação da "abolição da escravatura" como fato histórico que tenha vindo para libertar os negros escravizados do Brasil. Nesta cantiga, esta contestação pode ser encontrada nos versos: "Que eu venho daquela raça/ Que lutou pra se libertar.” Encontramos em outras cantigas referências com a mesma tônica como a de Rose Meire Sant'Anna Araújo, conhecida na capoeira como Speed, cujo trecho destacamos:

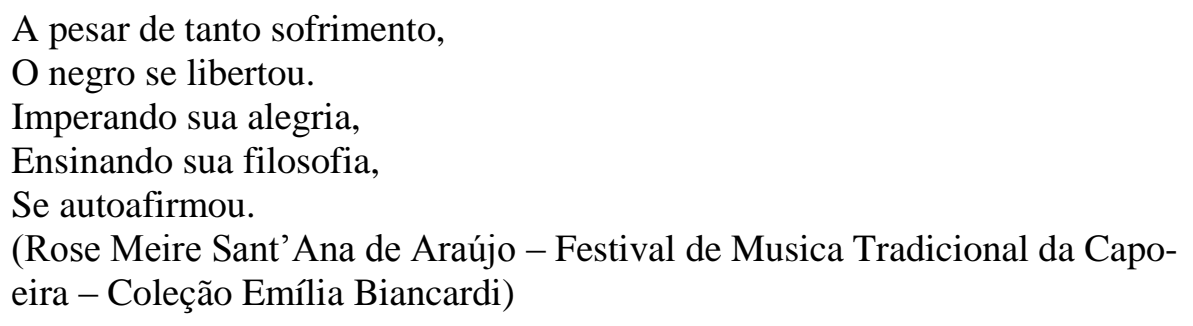

Sobre o 13 de maio e o fim da escravidão, lembra-nos Albuquerque e Fraga (2006), "[...] os conflitos que ocuparam a política durante e depois do dia 13 de maio denunciavam que, nem de longe, a Lei Áurea encerrava a tensão "racial" que a escravidão produzira" (ALBUQUERQUE e FRAGA, 2006:203). Vemos nestas cantigas a manifestação de consciência política que se estabelece como fator essencial na construção das identidades culturais afro-brasileiras.

Os versos que se seguem, na citada cantiga do Mestre Ezequiel, mencionam outras instituições culturais criadas pelos africanos e afro-brasileiros como candomblé, samba e maculelê, construindo uma imagem idealizada e generalizadora do afro-brasileiro, como aquele que “acredita no candomblé/ Que tem o sorriso no rosto/ A ginga no corpo e o samba no pé”. Ao 
falar da capoeira, também uma instituição de origem afro-brasileira, se expressa na cantiga uma das suas ambiguidades: capoeira como dança e luta, também tratados como subcategorias desta pesquisa.

Nos dois últimos versos deste corrido percebemos a intenção de apaziguar os ânimos, visto que esta cantiga é uma resposta direcionada a quem usa pejorativamente o termo "negro," a fim de humilhar, constranger e discriminar, expressando seu preconceito "racial". Por isso, termina a cantiga lembrando o que muitos mestres falam, que a capoeira aceita a todos, independentemente de "raça", credo ou cor. Ou seja, na roda de capoeira todos são "camarados10" independente das desavenças de outras ordens, por isso "brancos e negros na roda/ se abraçam como irmãos".

De modo geral compreendemos que todas as cantigas que procuram seguir os padrões tradicionais destas cantigas, de certo modo se propõem à valorização da identidade cultural afro-brasileira.

Na segunda categoria, que reflete sobre as pessoas de referências cantadas nas cantigas de capoeira, subcategorizamos em Mestres e Heróis. De modo geral, os objetivos e as temáticas das cantigas que encontramos, principalmente nas ladainhas da capoeira angola e nas quadras da capoeira regional, têm o notório intento de prestar homenagens aos grandes mestres da capoeira, como Valdemar, Bimba e Pastinha; aos heróis da capoeira, como Besouro Mangangá; e a personagens históricos significativos na luta pela liberdade do negro escravizado, como Zumbi. Ao cantar fatos da vida dos mestres e heróis, busca-se assegurar que outros capoeiristas também conhecerão a sua história. Isto pode ser compreendido como uma forte manifestação da "ancianidade", um valor afro-brasileiro que se faz presente no mundo da capoeira através da reverência aos mais velhos. Esta reverência continua mesmo após sua morte, quando se acredita, também na capoeira, que o ente passa a habitar em uma outra dimensão, à qual o nosso corpo físico não tem acesso, tornando-se assim um ancestral.

No mundo da capoeira é muito comum o aluno ou discípulo se referir e se alocar à linhagem atribuída ao seu mestre. Por exemplo: Mestre Marcelo de João Pequeno, discípulo de

\footnotetext{
10 Termo usado pelos antigos mestres da capoeira e ainda presente em muitas cantigas. É o mesmo que camarada, conhecido ou companheiro.
} 
João Pequeno de Pastinha; Mestre João Pequeno de Pastinha, discípulo de Mestre Pastinha. Deste modo, o aluno se localiza no mundo da capoeira através dos referenciais dos mestres. Cumpre salientar, que na capoeira, a linhagem é percebida da mesma forma como é compreendida em algumas religiões de matriz africana, como os candomblés. Conforme o conceito fornecido por Muniz Sodré (2002),

[...] linhagem, ou seja, o conjunto das relações de ascendência e descendência regido por uma ancestralidade que não se define apenas biologicamente, mas também política, mítica, ideologicamente. [...] Isto é precisamente linhagem: um grupo ao mesmo tempo real e simbólico (SODRÉ, 2002:74).

Estabelecemos a categoria Elementos do Mundo da Capoeira, com as subcategorias Ginga, Instrumentos e Fundamentos, contudo sabemos que a capoeira possui uma vasta lista de elementos. Estas subcategorias foram estabelecidas como tal devido ao vasto aparecimento destes itens nas cantigas. Algumas cantigas giram em torno de um destes elementos a partir do qual diversas metáforas são apresentadas estabelecendo relação entre o elemento, a vida e a roda da capoeira, em outras cantigas, aparecem compondo o refrão, assim, repetido diversas vezes durante a cantoria.

Em relação aos fundamentos, que nas religiões de matrizes africanas como o candomblé são considerados "segredo," acessível aos que preenchem determinados requisitos como o tempo de permanência na casa, as iniciações e o cumprimento das obrigações, que estabelecem uma hierarquia, na capoeira podemos perceber como algo que é passado principalmente nas aulas, nas conversas com os mestres, nas rodas e nas cantigas. Na capoeira, a passagem dos fundamentos é uma das tarefas do mestre, pois são vistos como parte do jogo, contudo a apropriação destes depende muito mais dos alunos. Entre os mestres, os valores fundamentais não são institucionalizados, podendo variar de acordo com o pensamento de cada um. Percebemos que os fundamentos variam de acordo com o mestre ou o grupo, e a aquisição destes fundamentos não depende unicamente dos ensinamentos passado, mas do desenvolvimento do aluno na capoeira.

Nas palavras transcritas abaixo, ditas pelo Mestre Valdec, notamos que, mesmo não havendo um rol fixo dos fundamentos da capoeira, o domínio desses elementos é, ou deveria ser, um requisito essencial na formação do mestre, em suas palavras: 
Um aluno não pode ser graduado mestre se ele não domina todos os fundamentos. Por mais excepcional que o aluno seja você não vai graduar ele com pouco tempo, mas eu acredito também que tem outros valores. Tem aluno que tem até tempo, ele faz muitas coisas, mas não domina o fundamento. (Mestre Valdec em entrevista concedida à pesquisa) (Grifos da autora).

A partir da fala do Mestre Valdec verificamos que o tempo, a observação e o exercício são práticas que viabilizam a apropriação dos fundamentos, e o domínio destes constitui-se requisito para a graduação do discípulo em mestre.

O estabelecimento da categoria que trata sobre O Espaço: a Bahia, o Brasil, a África e Angola, vem da constatação de que estes espaços são locais de referência para os capoeiristas a julgar pelo sem número de cantigas que esses são mencionados, homenageados e, muitas vezes, idealizados. Podemos perceber - nas cantigas analisadas - a presença da África e de Angola como locais de referência da construção da identidade afro-brasileira dos capoeiristas de Salvador, enquanto o Brasil, a Bahia e Salvador - que aparecem em muitas dessas cantigas - exprimem o sentimento dúbio de sofrimento e superação, associado à história do negro brasileiro. Observamos que em grande parte das cantigas de capoeira de Salvador, os termos Bahia e Salvador muitas vezes se complementam, ou tornam-se sinônimos. Por fim, na maioria das vezes estes locais referem-se às origens da capoeira ou do afro-brasileiro que, por sua vez, reporta-nos à quinta categoria da análise estabelecida, que trata das narrativas.

As narrativas, como categoria, está subdividida em duas subcategorias: História do Negro e as Experiências e Causos. Algumas cantigas de capoeira unem elementos da experiência pessoal e mística do autor com fatos do cotidiano e sua religiosidade. Também notamos outra linha de composição das cantigas de capoeira de Salvador, também narradas em primeira pessoa, que são assim apresentadas e mostram alguns fatos contraditórios e/ou idealizados, com isso, observamos que as cantigas da capoeira são, em muito, embasadas no que se conhece através da tradição oral, passada principalmente através dos mais experientes na capoeira, e também do que se aprende na escola formal, nas aulas de História do Brasil. Contudo, salientamos que a História oficial não tenha se preocupado em registrar as narrativas e fatos relevantes para os negros escravizados, desde a sua chegada ao Brasil, mas sim, o que era importante para seus comércios e demais atividades modos de dominação. Desta forma, vemos que 
a memória foi um modo de registro daquilo que acontecia, e era transmitido oralmente, devido à importância da tradição oral entre a maioria dos grupos escravizados.

A última categoria reflete sobre as Definições Sobre a Capoeira que se apresentam subcategorizadas em Esporte, Arte, Luta, Cultura e Ritualidade. Afinal, o que é a capoeira para os capoeiristas? De acordo com as cantigas analisadas, pode-se dizer que é tudo isso e mais um pouco. Como observa a célebre frase do filósofo da capoeira, o Mestre Pastinha, "Capoeira é tudo o que a boca come", podendo até ser uma arma mortal, conforme a cantiga que diz “Zum, zum, zum / Capoeira mata um” (autor anônimo). Capoeira é arma de defesa pessoal e também ideológica, como corroboram as cantigas do Mestre Brasília em destaque:

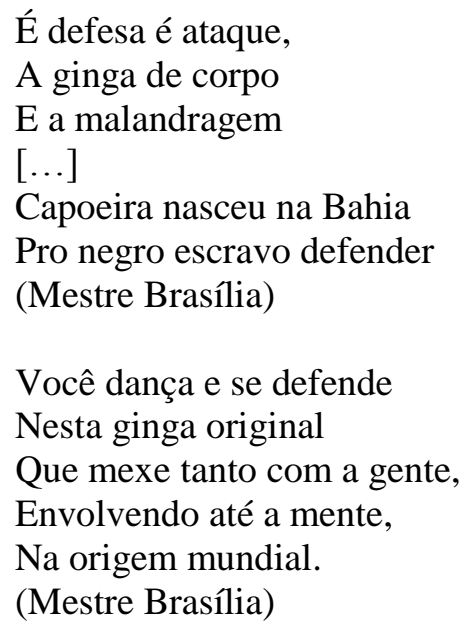

Procuramos aqui apresentar as cantigas de capoeira, pontuando como estas se relacionam à construção da identidade cultural afro-brasileira por transmitir valores, princípios e um pouco da História e dos africanos e afrodescendentes no Brasil, com isso contribui para uma reflexão sobre o lugar atual do negro afro-brasileiro na sociedade. Assim, percebemos através das categorias - algumas delas aqui elencadas - elementos do universo afro-brasileiro que são imbricadas na formação desta identidade cultural. 


\section{CONCLUSÃO}

A capoeira, muito antes do seu reconhecimento como patrimônio cultural brasileiro em 2008, integra o conjunto da cultura nacional,11 não apenas como uma das suas formas de expressão, mas também como discurso de liberdade, resistência e luta por valores com os quais nos identificamos como sujeitos da cultura afro-brasileira. Deste modo, a representação cultural da capoeira mostra-se cara aos afrodescendentes, como um fator de afirmação identitária e de sua luta social e política, ou seja,

A performance da capoeira é um drama narrativo. Cada vez que ocorre, ela evoca o ato escravo da rebelião. É digno de nota que a performance da capoeira somente reencena o confronto, a verdadeira luta entre escravo e seu opressor, e não retrata sua lógica conclusão: a fuga. (AQUINO, apud. REIS 2000:180). (Grifo da autora)

Neste sentido, procuramos evidenciar ao longo do trabalho que a capoeira nasce do contexto da escravidão colonial no Brasil e se apresenta como forma de luta e resistência física e ideológica, transmitida através da memória e da oralidade, como podemos ver nas narrativas, nos modos de vida, na corporeidade e nas cantigas dos mestres e capoeiristas. A capoeira é, portanto, outro canal de expressão de "fundamentos" e valores do universo afro-brasileiro.

Vimos ao longo deste trabalho que a capoeira é uma tradição multifacetada que teve seu início no encontro, forçado, entre diversas etnias, às quais pertenciam negros africanos escravizados e seus descendentes no Brasil, e que revelou seu caráter de luta e resistência libertária. Vimos também que a capoeira vem sendo recriada pelos próprios sujeitos que a praticam, e ressignificam esta tradição, inovando, criando novos estilos de capoeira, tanto do ponto de vista técnico quanto simbólico.

Considerando os novos contextos nos quais estamos inseridos e nos quais a capoeira opera em conjunto, como os novos meios de comunicação e registro e demais benefícios proporcionados pelos avanços tecnológicos, bem como as novas frentes de batalha e resistência

\footnotetext{
11 Tomamos o conceito de Stuart Hall acerca das "culturas nacionais como comunidades imaginadas" e salientamos o aspecto da cultura nacional apresentar-se segundo o autor, como "uma das principais fontes de identidade cultural" (2006:47).
} 
Pontos de Interrogação, v. 3, n. 2, jul./dez. 2013

Revista do Programa de Pós-Graduação em Crítica Cultural

Universidade do Estado da Bahia (UNEB), Campus II - Alagoinhas - BA

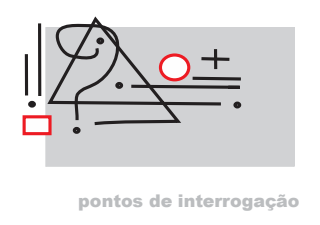

que buscam, não a tolerância, mas o respeito à diversidade étnica e "racial", à cultura e aos valores afro-brasileiros, dentre os quais os movimentos sociais, acadêmicos e culturais, podemos perceber que, de modo geral, a capoeira ainda hoje continua expressando seu caráter dinâmico e de luta social e política no combate à discriminação e marginalização dos afrodescendentes.

Assim, pôde-se observar, ao longo deste trabalho que a capoeira expressa seu caráter ambíguo de diversos modos. Tanto por estar ancorado entre as categorias de luta, jogo e dança, quanto pelo viés histórico que a relaciona à trajetória dos negros no Brasil. Podemos ainda ver seu aspecto cultural, social e político, que tem como diferencial uma série de elementos que entram em cena no momento da roda, dentro e fora dela, e que lhe dão maior complexidade em ordem social e simbólica.

Com base na metodologia das representações sociais, buscamos identificar nas falas dos capoeiristas, através das entrevistas e das cantigas que também foram tomadas como a fala enunciada pelos próprios capoeiristas. (Ou seja, eles são os principais sujeitos desta expressão) Sendo assim podemos refletir sobre as representações que os capoeiristas constroem de si e da sua identidade, como sujeitos da cultura afro-brasileira e - desta forma - analisar como estas se encontram expressadas nas cantigas da capoeira.

De modo geral, notamos que as referências aos valores e a história dos afro-brasileiros permeiam quase todas as cantigas, apresentando-se principalmente como resultantes das lembranças do tempo da escravidão. Neste caso, evidencia-se a memória e a oralidade como principais valores envolvidos neste processo de criação.

Tais referências ocorrem nas cantigas, tanto através de ideias estruturadas em versos, como através de palavras específicas que remetem ao discurso da identidade afro-brasileira. Assim, percebemos, como na cantiga que diz: "Vou dizer ao meu sinhô, que a manteiga derramô", de autoria desconhecida, algo que remete à relação "senhor-escravo". Neste sentido, notamos a construção de um todo de referências da identidade afro-brasileira, que é maior que a soma das suas partes. Deste modo, percebemos que os capoeiristas, na composição das suas cantigas, buscam declaradamente expressar valores, histórias e experiências relacionadas ao universo afro-brasileiro, e esta intencionalidade pode ser vista pelos mesmos como principal elemento das cantigas tradicionais da capoeira. Por este motivo, muitos capoeiristas reprovam 
a execução de cantigas de outras formas de composição, as que não seguem os modelos das ladainhas, quadras, chulas ou corridos, e que não tenham a intenção de falar sobre o universo afro-brasileiro.

\section{REFERÊNCIAS}

ALBUQUERQUE, Walmyra R. de, FRAGA FILHO, Walter. Uma História do negro no Brasil. CEAO, Salvador; Fundação Palmares. Brasília, 2006.

BIANCARDI, Emília. Raízes musicais da Bahia. Salvador: Omar G., 2006.

GIL, Gilberto, A Grande Refazenda. SANTOS, Waldomiro Júnior, org. A grande Refazenda: África e Diáspora pós II CIAD. $1^{\mathrm{a}}$ Edição, Fundação Palmares, Brasília,

2007.

HOLANDA, Sérgio Buarque de. Raízes do Brasil. São Paulo, Cia das Letras, 1999.

KUBOHARA, Shinji. Vamos cantar, câmara. Vadiação. Salvador, Bahia, 2009.

LUZ, Marco Aurélio de Oliveira. Agadá: dinâmica da civilização afro-brasileira. 2. ed. Salvador: EDUFBA, 2000.

MINTZ, Sidney W. e PRICE, Richard. O nascimento da cultura afro-americana. Uma perspectiva antropológica. Tradução Vera Ribeiro. Rio de Janeiro: Pallas/ Universidade Cândido Mendes, 2003.

MUNANGA, Kabenguele. Negritude Afro-brasileira: perspectivas e dificuldades. In: Revista de Antropologia. Vol. 33, 1990. p. 109 - 117. Disponível em < http://www.acaoeducativa.org.br/downloads/09abordagem.pdf >. Acesso em 20 de maio de 2011.

Uma abordagem conceitual das nações de raça, racismo, identidade e etnia. Palestra proferida no $3^{\circ}$ Seminário Nacional Relações Raciais e Educação - PENESB-RJ, 05/11/2003.

REIS, Letícia Vidor de Souza. $O$ mundo de pernas para o ar: a capoeira no Brasil. Publisher Brasil, São Paulo, 2000.

SOARES, Carlos Eugênio Líbano. A negregada instituição: os capoeiras no Tio de Janeiro 1850 - 1890. Rio de Janeiro, Secretaria Municipal de Cultura. Departamento Geral de Documentação e Informação Cultural, Divisão de Editoração. 1962.

SODRÉ, Muniz. Samba, o dono do corpo. Codecri, Rio de Janeiro, 1979. 
O terreiro e a cidade: a forma social negro brasileira. Imago, Rio de Janeiro; FUNCEB, Prosa e Poesia, Salvador, 2002.

TRINDADE, Azoilda Loretto da. Valores civilizatórios afro-brasileiros na educação infantil. In: Ministério da Educação, Valores afro-brasileiros - Boletim 22 novembro de 2005. p. 30 36 .

\section{Arquivo}

Arquivo pessoal de Emília Biancadri - Festival de música tradicional da capoeira (Primeira e segunda edição).

Recebido em: 08 de novembro de 2013.

Aprovado em: 02 de dezembro de 2013. 
